\title{
Planejamento das aulas no cotidiano da alfabetização: práticas, perspectivas e desafios
}

\begin{abstract}
RESUMO: Neste texto apresentamos resultados de uma pesquisa realizada no ano de 2018, com professoras alfabetizadoras de um município do interior do Rio Grande do Sul, as quais participaram da formação no âmbito do Pacto Nacional pela Alfabetização na Idade Certa - PNAIC 2017/2018. Problematizamos acerca da prática de planejamento das aulas pautados por referenciais que discutem o trabalho docente pelo viés coletivo e reflexivo na ação alfabetizadora e algumas das orientações dos Cadernos de Formação do PNAIC 2012 e 2014. Trata-se de uma pesquisa qualitativa orientada pela abordagem exploratória que teve como instrumento para produção dos dados um questionário que contemplou o total de 22 professoras alfabetizadoras atuantes no $3^{\circ}$ ano. Os dados nos permitem afirmar que há uma prática de planejamento que ora acontece de forma individual e ora coletiva e que as condições de trabalho dessas profissionais nem sempre favorecem os encontros. Percebemos que as áreas de conhecimento mais abordadas por essas alfabetizadoras são a linguagem e matemática por acreditarem que no $3^{\circ}$ ano do ciclo da alfabetização o domínio da leitura e escrita e os conceitos matemáticos precisam ser consolidados. Por fim, existe uma tendência forte de práticas de planejamento integrado.
\end{abstract}

Palavras- chave: Planejamento. Alfabetização. Práticas pedagógicas.

\section{Introdução}

Neste texto, apresentamos resultados de uma pesquisa realizada no ano de 2018, com professoras alfabetizadoras ${ }^{1}$ de um município do interior do Rio Grande do Sul, as quais participaram da formação no âmbito do Pacto Nacional pela Alfabetização na Idade Certa - PNAIC 2017/2018. ${ }^{2}$ O interesse em pesquisar sobre o tema do planejamento na alfabetização emerge das experiências de formação continuada de alfabetizadores, especialmente nesta já citada acima. Na ocasião, fomos responsáveis pela formação, estando completamente implicadas no desenvolvimento do processo formativo dessas professoras, evidenciando em diversos momentos, aspectos relevantes que emergiam do grupo, como, por exemplo, diferenças e contradições nas concepções sobre planejamento explicitadas por elas em perguntas e afirmações.

Diante da amplitude da temática do planejamento, focamos a pesquisa sobre como as professoras organizam o planejamento das suas aulas. Contudo, consideramos importante conhecer o perfil de quem está atuando nas classes de alfabetização, por
Silvana Maria Bellé Zasso Universidade Federal do Rio Grande (FURG) szasso2006@gmail.com Paula Pires da Silva Secretaria de Município da Educação do Rio Grande (SMEd) pfppires@hotmail.com Daniele Simões Borges Secretaria de Município da Educação do Rio Grande (SMEd) daniele.uab@gmail.com

(1) Usaremos durante todo o texto o substantivo no feminino, já que os sujeitos envolvidos na pesquisa eram todas mulheres.

(2) Esta etapa do Pacto de Alfabetização na Idade certa iniciou em novembro/dezembro de 2017 com o processo de organização, mapeamento, seleção do grupo de trabalho, reuniões de estudo e planejamento com as formadoras regionais; mais efetivamente à distância por conta da proximidade do final do ano letivo, com os formadores locais e professores alfabetizadores e, de forma presencial, no primeiro semestre de 2018. 
(3) A formação pelo PNAIC no município onde realizamos a pesquisa foi ofertada aos professores alfabetizadores em caráter de convite. Os encontros aconteceram no período da Hora Atividade, o que explica a ausência de uma parcela dos alfabetizadores da rede, já que não é a totalidade das escolas que têm garantido este espaço/tempo na carga horária do professor. acreditarmos ser um dado significativo para pensarmos as políticas de formação de professores, bem como, inferir análises sobre a prática de planejamento das aulas. Objetivando dar conta destes pontos que consideramos cruciais nesta pesquisa, organizamos o trabalho em seções.

Na primeira, apresentamos problematizações acerca da prática de planejamento das aulas como uma atividade reflexiva permanente e importante na profissão docente, pautados por referenciais de Nery (2007), Corsino (2007), Leal (2005), Morais (2019), Sá e Lima (2015), Imbernón (2009, 2010, 2011) e Nóvoa (1991) que discutem sobre a prática e o trabalho docente coletivo e reflexivo na ação alfabetizadora. Além disso, tratamos das orientações dos Cadernos de Formação do PNAIC 2012 e 2014.

Na segunda seção tratamos da abordagem metodológica sustentados nos princípios da pesquisa qualitativa (GIL, 2010; LAVILLE; DIONNE, 1999), que nos orienta no sentido de compreender que o pesquisador é como um ator que constrói os dados; influencia e é influenciado por eles e neste movimento vai "descobrindo" as significações produzidas tanto pelo participante como pelo pesquisador no tratamento dos dados produzidos. Destacamos que do total de 300 alfabetizadoras da rede pública municipal, ${ }^{3}$ estavam presentes na última etapa da formação, em 2018, apenas 109 professoras as quais protagonizaram o desenvolvimento desta pesquisa.

$\mathrm{Na}$ terceira seção, apresentamos o perfil das professoras alfabetizadoras construindo um panorama sobre quem eram as professoras que atuavam, naquele momento, no $3^{\circ}$ ano do ciclo da alfabetização. Na última seção, os dados sobre as práticas de planejamento das professoras, alguns aspectos do cotidiano destas práticas no que se refere a forma como a realizam; as referências que buscam para planejar; as articulações entre as áreas de conhecimento; seus desafios na dinâmica do trabalho e a articulação destes com os demais níveis de planejamento na escola.

No encaminhamento das discussões tecemos algumas considerações a respeito do que a pesquisa nos permite afirmar depois do caminho percorrido e quais questionamentos nos apontam a seguir. 


\section{A prática de planejamento na sala de aula de alfabetização de crianças}

Temos defendido que o planejamento das aulas se constitui no eixo estruturante da prática pedagógica, pois ele além de organizar o trabalho pedagógico concretiza a intencionalidade do fazer docente. Entendemos que para os docentes, mesmo diante de vários desafios que enfrentam nas condições de trabalho e nas adversidades da rotina escolar e pessoal, ainda assim, a prática de planejamento é condição na profissão docente. (NÓVOA, 1991) Desse modo, compreendemos que a professora alfabetizadora, ao produzir seu planejamento, não apenas organiza o cotidiano da sala de aula, como igualmente expressa por meio deste os objetivos e as concepções teóricas que as constituí posto que "é por meio da elaboração do planejamento, de seu desenvolvimento e de sua avaliação que a escola afirma a sua autonomia e o seu saber específico". (BATISTA, 2005, p. 9)

Numa perspectiva histórica, houve nas décadas de 1980 e 1990, a discussão das teorias construtivistas quando tivemos, no Brasil, uma crítica intensa aos modelos pré-estabelecidos de rotinas e planejamento das aulas e estas foram compreendidas, por muitos professores, como a abolição desta prática importante da docência. Soares (2004) vai explicar que nos anos 1990, vivemos um momento de "desinvenção da alfabetização" alavancada pela ausência de metodologias para alfabetizar. Ou seja, os métodos tradicionais foram, em grande parte, abandonados, porém metodologicamente podemos observar uma lacuna acerca da própria especificidade da tarefa de alfabetizar, o que influenciou, no nosso ponto de vista, nas práticas de planejamento das alfabetizadoras.

Desse modo, conforme Soares (2004) em virtude dessas mudanças teóricas no campo da alfabetização se expandiram os estudos sobre o conceito de letramento. Assim, o arranjo teórico e metodológico foi se alterando e a proposta de Soares (2004) de alfabetizar letrando, aos poucos, foi figurando na literatura nacional e nas propostas curriculares que sucederam este momento. De acordo com a referida autora já não podíamos mais pensar numa abordagem mecânica para alfabetizar, mas considerar que alguns conhecimentos relacionados à leitura e a escrita estariam presentes em práticas sociais diversas - antes mesmo de a criança estar no contexto escolar. No entanto, isso não dispensaria o ensino 
(4) Esses índices são divulgados pelo Instituto Nacional de Estudos e Pesquisas Educacionais Anísio Teixeira (Inep) através da realização de avaliações em larga escala com estudantes em todo país.

(5) Podemos destacar o Programa toda Criança Aprendendo de 2003; o Programa Pró-Letramento de 2005, e, sendo uma de nossas referências neste trabalho, o programa Pacto Nacional pela

Alfabetização na Idade Certa em

(6) Melo (2015, p. 162-163)

argumenta que, dado os aspectos positivos proporcionados pelo PNAIC, é preciso levar em consideração algumas insuficiências na prática escolar, pela falta de políticas públicas educacionais que envolvem infra estrutura, condições de trabalho, atendimento às crianças deficientes ou com dificuldades de aprendizagem, etc. sistemático da escrita alfabética em sala de aula, e todo o trabalho docente que é empreendido para isso. (SOARES, 2004)

Além disso, numa linha geral, o conjunto de políticas educacionais desenvolvidas no que concerne a alfabetização foi historicamente baseadas em proposições de reformas curriculares, com pouca ou nenhuma apreensão do cotidiano vivenciado nas escolas e dos desafios da sala de aula, mas sim com forte interesse no melhoramento dos índices ${ }^{4}$ da alfabetização. Nesse horizonte, nos anos 2000, mais precisamente, podemos observar o investimento em Programas ${ }^{5}$ de formação de professores, levando em consideração as discussões paradigmáticas que envolvem o processo de alfabetização, valorizando a profissionalização e destacando o planejamento pedagógico como uma ação de produção do conhecimento docente.

Nesse sentido, um aporte condizente com as questões salientadas acima, são as discussões apresentadas nos Cadernos de Formação do Pacto Nacional pela Alfabetização na Idade Certa - PNAIC (2012), ao tratar da organização do trabalho pedagógico, vislumbra a possibilidade do desenvolvimento de um currículo para a alfabetização que realmente garanta o direito à educação e os direitos das crianças enquanto protagonistas nesse processo, demonstrando o papel crucial que a ação de planejar exerce nas práticas pedagógicas cotidianas. Os cadernos ressaltam que:

[...] por meio de uma interpretação equivocada da teoria construtivista, passou-se a criticar tudo o que se relacionava com planejamento e organização do trabalho pedagógico com a justificativa de que era 'tradicional', velho e ultrapassado. Tal fato fez crescer um discurso em prol da não sistematização do ensino e da falta de programação das atividades, com a justificativa de que o trabalho de sala de aula deveria considerar apenas o que os alunos traziam da sua realidade. O professor, nesse contexto, seria o mediador desses conhecimentos na sua prática cotidiana escolar e não precisaria se programar para realizar as atividades, pois estas iriam surgir na própria prática cotidiana. Cadernos de Formação do PNAIC ANO 1- UNIDADE 2. (BRASIL, 2012, p. 19)

Essas leituras equivocadas podem ter favorecido para uma escassa organização do trabalho pedagógico e do acompanhamento da aprendizagem das crianças, bem como para a explicitação da intencionalidade das aulas gerando, de certa forma, uma diminuição 
da importância do planejamento enquanto ação fundamental do trabalho docente.

Entretanto, na década de 2000 se intensificam as discussões acerca da prática do planejamento nos anos iniciais de uma forma integrada, ou seja, que os planos de aulas apresentem atividades que articulem as diferentes áreas de conhecimento, pois desta forma elas propiciam maior sentido aos conteúdos, potencializando a aprendizagem. Temos discutido no campo da alfabetização a necessidade de planejar em uma perspectiva de integração curricular (CORSINO, 2007; NERY 2007; SÁ; LIMA, 2015) isto é, planejar numa estrutura organizativa de projetos pedagógicos, sequências didáticas, atividades permanentes e de sistematização que possibilitem articular as diversas áreas de conhecimento.

Sendo assim, essa perspectiva de integração curricular auxilia o trabalho da professora diante da heterogeneidade apresentada por um grupo de crianças em processo de alfabetização bem como não podemos imaginar que apenas um modelo de planejamento e organização de atividades contemplará todas as facetas da aprendizagem da escrita e da leitura.

Contudo, esse olhar diferenciado e atento para heterogeneidade da sala de aula, que exige a docência na alfabetização, deve ser estendida às infâncias, pois as alfabetizadoras ao terem um "olhar sensível das produções infantis poderão conhecer os interesses das crianças e os conhecimentos que estão sendo apropriados por elas" (CORSINO, 2007, p. 57) o que 1hes permitirá intencionalizar as intervenções e propostas que vêm realizando, porque as perguntas, dúvidas e os "erros" cometidos pelas crianças em processo de alfabetização são dados valiosos para a intervenção das professoras e, por conseguinte, a seus planejamentos. A clareza da intencionalidade do trabalho pedagógico fará diferença nas ações de sala de aula e no processo de apropriação da leitura e da escrita, por isso insistimos de que esta prática precisa ser vivida pelas professoras alfabetizadoras no cotidiano da docência, porque,

Um dos elementos centrais para o sucesso escolar, em especial no ciclo de alfabetização, é o desempenho e as atribuições assumidas e conferidas aos professores. Acreditamos na capacidade do professor em desenvolver sua prática com qualidade e de forma coerente através do diálogo com seus pares na escola e com os materiais curriculares. Cremos que o planejamento é um dos meios para se programar as ações 
docentes, um momento inicialmente pensado no coletivo da escola, que requer consciência do que se deseja fazer durante o ano letivo. (BRASIL, 2014, p. 7)

Assim, os momentos de planejamentos compartilhados por ano ou nível de ensino são muito importantes, tanto para a definição dos objetivos mais amplos do planejamento, quanto para os mais específicos do cotidiano da sala de aula, pois tais práticas darão maior orientação às suas ações na sala de aula e nas diferentes funções que podem ocupar na instituição. Nesse sentido, Batista (2005) também sugere o planejamento em diálogo com os pares e afirma que esta prática auxilia o docente para o desenvolvimento do processo de ensino e aprendizagem de maneira sistemática. Para o autor, o planejamento compartilhado deve ter como prisma a aprendizagem do estudante, por essa razão a partilha entre os docentes contribuiu para perceber, pela variação de concepções, questões relacionadas continuidade das aulas; a organização do currículo segundo a complexidade dos conhecimentos abordados e, também ao estabelecimento das finalidades a serem alcançadas para cada nível ou ano de ensino. (BATISTA, 2005) Desse modo, além da prática de planejamento compartilhado é necessário ter compreensão sobre o foco de cada etapa do ensino. Considerando o início do Ensino Fundamental, que tem o propósito de ensinar as crianças a ler e escrever, Morais (2019, p. 134) ressalta que:

O primeiro ano do ciclo de alfabetização continua sendo uma etapa em que as crianças precisam ser ajudadas a desenvolverem as habilidades metafonológicas que participam do complexo processo de apropriação da escrita alfabética, quando, como demonstrou a teoria da psicogênese, avançam em suas hipóteses sobre o que a escrita nota e como ela cria notações.

Confirmando as ideias até aqui defendidas, Corsino (2007) afirma que o conhecimento é uma construção coletiva e é na troca de sentidos construídos, no diálogo e na valorização das diferentes vozes que circulam nos espaços de interação que a aprendizagem vai se dando.

Ainda sobre a articulação a partir da interdisciplinaridade na alfabetização, Sá e Lima (2015) elucidam que a proposição do ciclo nos anos iniciais pressupõe a integração curricular como motriz do trabalho pedagógico. Ou seja, para estar a favor dos direitos de aprendizagem das crianças não cabe mais a estruturação rígida de 
uma sequência de conteúdos cumulativos e estanques. (SÁ; LIMA, 2015) Quando os planejamentos são organizados de forma articulada com as diversas áreas do conhecimento (ciências sociais, ciências naturais, noções lógico-matemáticas e linguagens), os princípios e propriedades do funcionamento da escrita alfabética são alicerçados em situações com mais sentido.

Sob esta ótica, a prática do planejamento compartilhado é processual e possui uma dimensão diagnóstica e outra formativa. Diagnóstica porque a avaliação é um ato contínuo neste processo. Precisamos avaliar tanto o processo de ensino como da aprendizagem por parte das crianças, levando em consideração seus interesses e expectativas. O planejamento não pode ser realizado apenas por parte da professora, necessariamente precisa estar acolhendo a perspectivas dos alunos. Desse modo, é formativo, pois como expõe Leal (2009, p. 3) planejar é "a atividade central da formação profissional do docente".

Diante dos desafios da prática de planejamento do professor, outro aspecto a ser refletido é sobre o papel dos formadores de professores. Imbernón (2009, p. 105) ressalta que:

Pouco a pouco foi surgindo a consciência de que o(a) formador(a) deve assumir mais um papel prático colaborador num modelo mais reflexivo, no qual será fundamental criar espaços de formação (ou de inovação ou pesquisa) para ajudar a analisar os obstáculos (individuais ou coletivos) que o professorado encontra para ter acesso a um projeto formativo que ajude a melhorar.

O referido autor traz para o debate a urgência de se pensar os processos de formação continuada dos professores a partir da escola. Ele acredita que "[...] a formação centrada na escola pretende estabelecer um paradigma colaborativo entre os professores". (IMBERNÓN, 2011, p. 85) Essas reflexões encontram diálogo com as ideias de Nóvoa (1991), que defende a escola como lócus de formação continuada do educador e atenta para o fato de que essa perspectiva não é simples e nem ocorre espontaneamente, ela é uma construção que só ganha vida quando passa da reflexão para a ação.

Acreditamos na ideia de que ao se estabelecer estes espaços formativos, promove-se uma cultura colaborativa defendida por Imbernón (2010) e esta passa a assumir um importante papel na 
(7) Desde 2017 com o Programa de Formação do Pacto Nacional pela Alfabetização na Idade Certa (PNAIC), que se estendeu durante o ano 2018 e mais recentemente em 2019, enquanto pesquisadoras e formadoras de professores, viemos realizando profícuas parcerias com a Secretaria de Município da Educação (SMEd). Procurando ofertar e ao mesmo tempo sanar uma demanda vinda da própria SMEd: uma proposta de formação continuada que atenda as reais necessidades dos docentes em especial os Alfabetizadores. (re)construção das identidades e saberes dos docentes, contribuindo sobremaneira nas práticas de planejamento das professoras por vivenciarem partilhas de dúvidas, dilemas e acertos no processo de alfabetização.

As atividades de formação continuada que temos desenvolvido têm nos possibilitado, por meio desta pesquisa, mapear as práticas de planejamento realizadas pelas professoras alfabetizadora e propiciado vivenciar este papel prático e reflexivo nas formações.

Sendo assim, na sequência do texto, tratamos dos procedimentos da metodológicos utilizados na pesquisa.

\section{Abordagem metodológica}

A pesquisa que apresentamos neste trabalho situa-se no campo da educação, mais especificamente, na formação de professores. Trata-se de uma pesquisa qualitativa, em que, segundo os estudos de Laville e Dionne (1999, p. 33, grifo nosso),

[...] o pesquisador é um ator porque ele precisa construir os seus dados. Eles defendem que os fatos dificilmente podem ser considerados como coisas, uma vez que os objetos de estudo pensam, agem e reagem, que são atores podendo orientar a situação de diversas maneiras, e igualmente o caso do pesquisador: ele também é um ator agindo e exercendo sua influência.

Alicerçadas nesta concepção nos propomos construir caminhos para atingir nossos objetivos situados na pesquisa qualitativa e orientada pela abordagem exploratória que, de acordo com Gil (2010), se constitui numa estratégia que oportuniza uma percepção geral do fenômeno investigado. Desse modo, para alcançarmos dados qualitativos importantes para o encaminhamento desta investigação foi utilizado como instrumento da pesquisa o questionário com questões abertas e fechadas.

Utilizamos o questionário com a intenção de reconhecer as práticas de planejamento das professoras alfabetizadoras que atuam em escolas públicas de um município do interior do Rio Grande do Sul, as quais participaram da formação promovida pelo PNAIC 2017/2018. Considerando que o número inicial de participantes poderia ser de 300 professoras optamos pelo uso do questionário 
por considerar o mais adequado e possível de ser realizado sem a presença do entrevistador.

Segundo Laville e Dionne (1999) o questionário tem vantagens como técnica de produção de dados que permite atingir um grande grupo favorecendo o pesquisador na compilação e na análise pormenorizadas das repostas. A partir desses pressupostos, o questionário foi dividido em duas partes: a primeira parte diz respeito ao perfil das professoras alfabetizadoras, pois fizemos um levantamento de aspectos referentes à formação e tempo de atuação no magistério destas docentes; a segunda parte focada nas práticas cotidianas de planejamento, desde a sua organização perpassando pelos desafios que encontram para realizar tal prática docente até sua articulação com outros níveis de planejamento na escola.

Nesse sentido, perguntamos sobre: a frequência que o planejamento das aulas é elaborado; se é uma ação individual ou coletiva; se existe um roteiro; o que tomam por referência para elaborar o planejamento - conteúdo, áreas de conhecimento, temáticas, tipos de atividades, sites da internet, entre outros aspectos -; de que forma selecionam o que é trabalhado em cada aula; quais os principais desafios que encontram na prática de planejamento; quais as áreas de conhecimentos que considera mais contemplada no planejamento semanal e por quê; se as condições de trabalho que tem atualmente favorecem para a elaboração do planejamento das aulas; justificar se na opinião delas consegue fazer um planejamento integrado. E, por fim, se existe articulação entre o planejamento das aulas com o projeto pedagógico da escola e demais planejamentos.

Os dados foram analisados e discutidos conforme a análise de conteúdo proposto por Laville e Dionne (1999) que orientam para um trabalho minucioso diante do dado bruto coletado. Neste processo realizamos a partir das respostas do questionário, um trabalho de descrição e categorização dos dados, pois para estes autores "[...] este é o princípio da análise de conteúdo: consiste em desmontar a estrutura e os elementos desse conteúdo para esclarecer suas diferentes características e extrair sua significação (LAVILLE; DIONNE, 1999, p. 214)

O questionário foi organizado de forma que pudéssemos visualizar o perfil das professoras participantes da pesquisa e mapear a prática de planejamento que realizavam. Dos 109 questionários aplicados, 65 foram respondidos por professoras que atuam no $1^{\circ}$, $2^{\circ}$ e $3^{\circ}$ ano do Ensino Fundamental; destes 65 questionários, 37 
professoras não autorizaram o uso dos dados para a pesquisa, sendo que, apenas 28 professoras autorizaram o uso das informações. Para o caso deste trabalho, optamos por considerar exclusivamente os questionários das professoras que atuavam apenas em um dos anos que compõe o ciclo da alfabetização. Assim, serão utilizados os dados de 22 participantes da pesquisa que autorizaram o uso de suas respostas e estavam atuando em 2018 no $3^{\circ}$ ano.

Considerando os questionários respondidos e autorizados, realizamos o procedimento de análise dos dados em três momentos. No primeiro momento, fizemos uma leitura atenta das respostas, tanto das questões objetivas quanto das discursivas. Os dados objetivos foram compilados e organizados em tabelas e os demais descritos para posterior análise. Após, foram destacados os enunciados mais recorrentes, dando visibilidade aos aspectos que no olhar das professoras eram pouco relevantes, importantes e discrepantes. No último momento, a partir dos objetivos do estudo exploratório, buscamos aproximações entre as respostas dos sujeitos. De acordo com a organização das questões apresentadas no questionário e da ênfase dada pelos sujeitos da pesquisa em suas respostas, foi possível destacar dois eixos de análise: a) o perfil das professoras alfabetizadoras e b) a prática do planejamento. Assunto que passamos a tratar na próxima seção.

\section{O perfil das professoras alfabetizadoras participantes da pesquisa}

Das 22 professoras participantes da pesquisa, 14 possuem formação no magistério em nível médio e, 20 delas também têm formação em nível superior, destas, 16 formadas em pedagogia. Constatamos também que 16 professoras realizaram pós-graduação em nível de especialização, cinco destas com mais de um curso e um possui curso de Mestrado. Os cursos de formação de professores aproximam-se e colaboram com a temática da Alfabetização, dentre os mais escolhidos temos a Psicopedagogia e a Orientação Pedagógica. Todas essas especializações foram realizadas após o ano 2000, o que indica tanto o interesse em continuar estudando, quanto a propagação de cursos em nível de especialização na modalidade a distância.

Esses dados demonstram que há um investimento na formação dos professores tanto em nível de graduação como em nível 
de pós-graduação coerente, de certa forma, com as políticas de formação inicial de professores que vem sendo fomentadas no país desde os anos 2000. Em relação à formação em âmbito de mestrado e doutorado, ainda é muito incipiente a continuidade desses estudos. Diante desse dado é importante problematizarmos acerca da necessidade de uma política de indução para a continuidade da formação em outros níveis da pós-graduação, tanto pela Secretaria de Município da Educação no que tange a flexibilização de horário, quanto na oferta de cursos na região.

Pinho (2009) sinaliza que o aprimoramento intelectual do professor incide no desempenho dos alunos, qualificando o saber docente e, por conseguinte, contemplando novos saberes em torno da educação, neste contexto outros conhecimentos em torno da alfabetização e da aprendizagem das crianças. Entretanto, sabemos dos diversos fatores que interferem neste aprimoramento, contudo, é necessário pensarmos em políticas de indução para a continuidade da qualificação do profissional que está atuando diretamente no ciclo da alfabetização

Os dados referentes ao tempo de docência em alfabetização mostram que a maioria das professoras está nos primeiros 10 anos de carreira. Com isso, é possível afirmar que a grande maioria delas exerce sua docência no ciclo de alfabetização em quase todo o tempo da carreira. Este dado nos permite inferir que há uma identificação das professoras com o campo da alfabetização.

Passamos agora a tratar do mapeamento que construímos sobre a prática do planejamento das professoras alfabetizadoras.

\section{A prática de planejamento das aulas: o que os dados indicam?}

Dentre as questões elaboradas para compreender como tem sido vivenciada esta prática pelas professoras alfabetizadoras, foi nosso interesse conhecer qual é a frequência que o planejamento é realizado por elas, sendo assim propusemos uma questão indicando três possibilidades a serem assinaladas: diário, semanal ou quinzenal. Nenhuma professora indicou que realiza o planejamento quinzenalmente, 14 professoras afirmaram que planejam semanalmente e oito planejam diariamente. Esta constatação evidencia, no nosso ponto de vista, um dado muito importante, qual seja, de que há a prática do planejamento sendo desenvolvida 
pelo grupo investigado, ou seja, suas intervenções pedagógicas não estão imersas ao acaso, mas estão sendo intencionalizadas. Leal (2009) ao abordar a prática do planejamento na alfabetização vem enfatizando a sua importância para a aprendizagem das propriedades do sistema de escrita alfabética, segundo a autora o planejamento organiza a realização de um trabalho pedagógico que prevaleça a intencionalidade do ensino por meio de uma ação educativa sistemática. Pudemos observar no grupo investigado que prevalece o planejamento semanal e diário o que possibilita o redimensionamento de sua prática à curto prazo sem perder de vista os objetivos mais amplos.

Defendemos que este planejamento semanal ou quinzenal deva ser sempre realizado com pauta no trabalho realizado na semana ou semanas anteriores, de forma que o professor que planejou avalie, revise o mesmo, no intuito de criar estratégias que retomem os aspectos conceituais e assim atinja os objetivos de aprendizagem pensados para aquela semana, mês, trimestre e assim sucessivamente conforme o ano letivo for transcorrendo. Sendo assim:

O que será trabalhado na semana precisa contribuir para a continuidade da aprendizagem dos alunos, de modo que eles avancem e ampliem o conhecimento [...]. Ao elaborar as sequências de atividades, será necessário pensar como essa sequência pode contribuir para a construção dos conceitos que serão trabalhados naquela aula. Os objetivos de aprendizagem necessitam estar explícitos no planejamento para que os alunos compreendam os conteúdos. As estratégias metodológicas e os recursos didáticos necessários para que ocorra aprendizagem deverão ser coerentes com o conteúdo que se pretende ensinar. (BRASIL, 2014, p. 10)

Também, buscamos compreender como esta prática de planejamento vem sendo vivenciada pelas professoras no cotidiano da escola, ou seja, se ele acontece de forma coletiva ou individual para entendermos se tais planejamentos são elaborados e ou discutidos entre os pares na escola. Os dados indicam que o planejamento é realizado tanto individual como coletivamente. Relatando suas investigações, Batista (2005) tematiza que na escola, para que o planejamento individual seja realizado é preciso de tempo e trabalho coletivo. E, nesta visão "Tempo é algo de que, em geral, os professores não dispõem. A maior parte dos docentes brasileiros 
possui contratos de trabalho que não prevêem tempos para atividade extra-classe e para o trabalho coletivo". (BATISTA, 2005, p. 11)

Diante disso, se compararmos o planejamento coletivo e o individual, constatamos a predominância da atividade solitária. As orientações das políticas educacionais atuais, mais precisamente na BNCC, defendem enquanto proposta para os professores, o planejamento por meio do trabalho cooperativo e em conjunto. (BRASIL, 2018) É uma preocupação que este planejamento seja processual e desenvolva o fortalecimento das relações e produção de projetos, envolvendo professores e comunidade escolar de forma coletiva.

Corroboramos com essa posição, no entanto, não podemos desconsiderar que as condições de trabalho das professoras conforme já ressaltado pelos estudos de Batista (2005), nem sempre favorecem a esta prática coletiva, pois muitos docentes que atuam no ciclo da alfabetização trabalham 40h semanais e, muitas vezes, em escolas diferentes, dificultando o encontro para a realização de estudos e práticas coletivas. Essa realidade foi apontada pelas pesquisadas quando questionadas se as condições de trabalho favoreciam a prática de planejamento das aulas. Vejamos alguns excertos:

Nem sempre! Pelos recursos disponiveis na escola. Cada ano que passa se torna mais curto os recursos. Falta materiais essenciais para um bom desenvolvimento das aulas. Até xerox é limitado, muitas vezes nem folha de oficio tem, embora a equipe diretiva esteja empenhada em procurar recursos (P.18).

Sim, este ano com os momentos de hora atividade foram importantes para a elaboração dos planos (P12).

O professor trabalha 20 horas e trabalha todas as horas, planejar fica dificil (P21).

Não. Uso meu tempo fora do expediente de trabalho, não tenho contribuições da coordenação e poucos materiais (P5).

Certamente, estas professoras retratam o cotidiano de muitos profissionais que atuam no ciclo da alfabetização. O tempo para se dedicar à atividade de planejamento nem sempre é garantido e a escassez de recursos humanos que enfrenta a maioria das escolas públicas brasileiras é um fato determinante. Nesse município, embora com avanços, ainda enfrenta a dificuldade da falta de professores para efetivar a hora atividade, quando isto é garantido, os horários 
deste período não coincidem com o turno das colegas do segmento, dificultando o encontro para a elaboração do planejamento de forma coletiva, justificando a predominância da prática individual do planejamento. Também, o escasso tempo para planejar dentro do seu turno de trabalho, faz com que o professor realize a atividade em outro tempo/espaço: em casa.

No que se refere à existência de um roteiro para realizar a prática de planejamento dez professoras responderam que sim, seguem um roteiro e a maioria, 12 professoras, respondeu que em parte há algum roteiro a ser seguido. O roteiro sinaliza também uma ação metodológica na prática do planejamento, no qual a professora tenha a visão do que pretende ensinar, do que é preciso recuperar e, não menos importante, dos processos avaliativos que intenciona realizar. Assim, podemos afirmar que a maioria das professoras realiza a prática de planejamento seguindo um roteiro, às vezes de forma coletiva e, muitas vezes, de forma solitária.

Quando questionadas sobre as alternativas de referência que elas tomam para realizar esta prática, as professoras elencaram por ordem de prioridade quais elementos que elegem ao planejar. A partir do levantamento das respostas, evidenciamos que a maioria das professoras opta por uma prática de planejamento integrado, pois tomam a "temática" como ponto de partida e, em seguida as "áreas de conhecimentos" para organização das atividades das aulas. A seleção de temáticas, pode se constituir numa estratégia importante para realizar articulações com as diferentes áreas do conhecimento. Essa prioridade dada pelas professoras as temáticas e áreas de conhecimentos ao planejar, encontra consonância com uma das modalidades de organização do trabalho pedagógico que Nery (2007, p. 119) defende - o projeto - por ele se constituir

[...] em um trabalho articulado em que as crianças usam de forma interativa as quatro atividades linguísticas básicas - falar/ ouvir, escrever /ler - a partir de muitos e variados gêneros textuais, nas várias áreas de conhecimentos, tendo em vista uma situação didática que poder ser significativa para elas.

O trabalho com Projetos e, outras modalidades de ensino que buscam a integração dos saberes, exige da professora conhecer o universo infantil ao qual ela está mediando a aprendizagem. Para isto conhecer as crianças e os objetivos das áreas de conhecimento 
de cada adiantamento é fundamental. De acordo com Corsino (2007, p. 58, grifo da autora):

Conhecer (as crianças), por sua vez implica sensibilidade, conhecimentos e disponibilidade para observar, indagar, devolver respostas para articular o que as crianças sabem com os objetivos das diferentes áreas do currículo. Implica também uma organização flexível, aberta ao novo e ao imprevisível; pois não há como ouvir as crianças e considerar suas falas, interesses e produções sem alterar a ordem inicial do trabalho, sem tornálo uma via de mão dupla onde as trocas mútuas sejam capazes de promover ampliações, provocar saltos dos conhecimentos.

A partir destas ideias de escuta das crianças, dos conhecimentos dos objetivos e da flexibilidade no planejamento, percebemos quanto a prática de planejamento exige a capacidade de estar num movimento dialético de (re)visitar e (re)elaborar as intenções previstas pela professora naquela aula, pois a contingência da sala de aula poderá redirecionar o planejado, mas sem perder de vista os objetivos curriculares. Por essa razão entendemos que para o planejamento ser realizado precisa do comprometimento das professoras alfabetizadoras, somente assim é que será alcançado o redimensionamento da ação pedagógica. Do exposto, entendemos que por meio do planejamento em ação também são observados quais os conhecimentos construídos pelas crianças e aqueles que precisarão ser melhor desenvolvidos. Ou seja, integrando a experiência das crianças e os diversos saberes almejados em uma proposta sistemática de ensino que prevê continuidade e aprofundamento dos conhecimentos, as práticas, na escola, serão qualificadas. Sobre o direcionamento do planejamento, as professoras entrevistadas puderam retratar como realizam a seleção do que é trabalhado em sala de aula. Vejamos o que expressam:

De acordo com as dificuldades individuais dos alunos, pois tenho uma turma muito diferenciada (P4).

De acordo com o interesse da turma, e dificuldades que os alunos apresentam durante as aulas. Com o objetivo de proporcionar uma aprendizagem prazerosa (P13).

Constatamos que a maioria das professoras têm por referência os interesses, as necessidades e as dificuldades dos alunos para 
propor as aulas. O que de certa forma parece atender o princípio pedagógico de partir da realidade da turma. Leal (2009), em seus estudos, defende que levar em consideração o interesse das crianças deve ser o elemento motriz para organização dos procedimentos no cotidiano escolar.

Sobre as áreas contempladas no planejamento semanal, a grande maioria (18) respondeu que o foco é na área da linguagem e matemática e justificaram tal ênfase pela preocupação em alfabetizar. Vejamos abaixo:

Considero a leitura/escrita/oralidade/raciocínio lógico. Penso ser devido a preocupação constante em alfabetizar, e ampliar a habilidade de escrita e leitura, e a necessidade de organização do pensamento através da fala, e a elaboração e uso dos conceitos matemáticos (P17).

Língua portuguesa (oralidade e escrita) e matemática, devido a extensão de conteúdos e habilidades a serem desenvolvidas e como no $3^{\circ}$ ano ainda se encontra muitos alunos no início do processo de alfabetização; acabo (reconheço ser uma lacuna) me detenho mais nesse processo. Os demais conhecimentos (ciências, história, geografia) vou adaptando e fazendo algumas atividades (P.19).

Considerando que as professoras atuavam no $3^{\circ}$ ano e, que este ano é considerado o último do Ciclo de Alfabetização $\left(1^{\circ}, 2^{\circ}\right.$ e $3^{\circ}$ anos), fica atrelado a ele uma maior responsabilidade ou cobrança sobre a consolidação do processo de alfabetização, pois a retenção/ reprovação já existe, não nos surpreende tais respostas. Esta situação impõe às professoras um compromisso que explica os argumentos utilizados para justificar esta ênfase. Também, de uma maneira geral, podemos afirmar que há um predomínio, histórico das áreas da linguagem e da matemática no currículo escolar da Educação Básica e, embora as orientações para o ciclo da alfabetização não sejam neste sentido, as professoras entrevistadas a explicitaram.

Um aspecto importante de ser considerado é o aumento do número de turmas de $3^{\circ}$ ano. Embora este não seja o objetivo deste trabalho, temos observado nas ações de formação continuada um discurso pedagógico que explicita vários fatores que podem ter contribuído para a produção deste fenômeno, dentre eles a interpretação equivocada da legislação que trata da progressão continuada, bem como a falta de uma proposta pedagógica bem articulada entre estes três primeiros anos 
Em relação ao planejamento integrado, a maioria afirmou realizar tentativas desta natureza, principalmente por meio dos projetos pedagógicos. De acordo com os estudos de Ferreira e Albuquerque (2012) um planejamento integrado contribui para que na ação pedagógica o professor tenha maior repertório didático no momento da prática, organizando os diferentes recursos, podendo perceber por meio de exercícios metodológicos diferentes, os desafios e necessidades cognitivas dos grupos de estudantes. Alguns excertos sobre este dado:

Sim, busco trazer relações entre as áreas do conhecimento de forma sistemática (P9).

Sempre que possivel tento integrar, mas em algumas disciplinas nem sempre é possível (P1).

Não, porque minha turma tem dificuldades no aprendizado variadas e aí faço atividades variadas (P4).

As respostas acima demonstram que a maioria dessas professoras elaboram planejamentos integrados, mas ainda encontram algumas dificuldades, ao mesmo tempo, em número menor, temos ainda profissionais que diante da heterogeneidade de aprendizagem da turma indicam certa dificuldade em abordar a integração das áreas em seus planejamentos de aula. Leal (2009) sugere que para aperfeiçoar esse aspecto no planejamento o professor precisa investir no registro diário das situações didáticas, e recorrer a estas no momento da produção de um novo planejamento.

Outro aspecto que abordamos na pesquisa sobre a prática de planejamento das aulas foi se havia articulação entre os níveis de planejamento escolar, ou seja, se a prática de planejar as aulas tomava por referência o Projeto Pedagógico da Escola e o Planejamento Anual Escolar. Em nosso ponto de vista, esta articulação é papel de uma instituição de ensino precisa construir propostas pedagógicas que envolvam todos da escola, isto é, professores, funcionários e comunidade em direção às intencionalidades, administrativas e pedagógicas ali definidas.

Observamos que 17 das professoras responderam que há articulação com os outros níveis de planejamento, indicando que a maioria das práticas de planejamento das aulas destas professoras, também está articulada a outros níveis de planejamento escolar que 
direcionam suas propostas no cotidiano da sala de aula. Algumas pontuaram a forma que vivenciam esta prática na escola que atuam:

Sim. O trabalho com o projeto está contemplado no P.P.P. Temos os projetos realizados nas turmas e temos um único da escola ao qual a professora busca vincular o seu com o mesmo (P11).

Sim, conforme o P.P.P. de minha escola, trabalhamos de maneira articulada, incentivando a inclusão, cooperação, a crítica, etc. (P15).

Sim, porque nas reuniões de formação de professores discutimos de forma coletiva os projetos e temáticas a serem trabalhados (P20).

Após este percurso investigativo, evidenciamos que desafios existem, principalmente, no que diz respeito às condições de trabalho destas profissionais, considerando que a maioria delas trabalham, muitas vezes, em mais de uma escola cumprindo uma jornada de $40 \mathrm{~h}$ semanais com turmas de currículo integrado. Seguimos na defesa da melhoria das condições de trabalho e qualidade das práticas alfabetizadoras.

\section{Considerações finais}

Neste artigo abordamos aspectos da prática de planejamento de um grupo de professoras alfabetizadoras e analisamos o perfil de formação. As ideias aqui trabalhadas foram sendo construídas a partir dos dados dos questionários respondidos e problematizamos sobre como tem sido o planejamento no cotidiano escolar. Entretanto, sabemos que poderá haver discrepância entre o dito e as práticas realizadas na escola.

Os dados indicaram que a maioria das participantes da pesquisa tem formação em nível superior e pós-graduação e, que a partir dos anos 2000, houve um maior movimento em direção à formação. Isto, a nosso ver, confirma a necessidade de políticas públicas de formação continuada permanente.

A partir desta investigação, podemos inferir que de uma maneira geral, há uma prática de planejamento que ora acontece de forma individual e ora coletiva e que as condições de trabalho destas profissionais nem sempre favorecem os encontros coletivos, bem como, para realizar esta prática no turno de trabalho, tendo que ser efetivada em seu tempo de descanso. 
Também percebemos que as áreas de conhecimento mais abordadas por estas alfabetizadoras são a linguagem e matemática por acreditarem que no $3^{\circ}$ ano do ciclo da alfabetização o domínio da leitura e escrita e os conceitos matemáticos precisam ser consolidados. Além disso, existe uma tendência forte de práticas de planejamento integrado que favorecem a uma perspectiva curricular interdisciplinar, mesmo que em alguns casos, encontrem dificuldades ao integrar algumas áreas por meio de diferentes estratégias.

Por fim, cabe salientar que desenvolver pesquisa situada em ações de extensão tem propiciado reflexões teórico metodológicas importantes que suscitam tanto o ensino da graduação como a definição de novas questões, que nos instigam e motivam a aprofundar estudos sobre as dificuldades de planejar de forma integrada.

\title{
Planning of classes in the daily life of literacy: practices, perspectives and challenges
}

\begin{abstract}
In this text we present the results of a survey conducted in 2018, with literacy teachers from a municipality in the interior of Rio Grande do Sul, who participated in the training carried out within the scope of the National Pact for Literacy at the Right Age - PNAIC 2017/2018. We problematize the practice of planning classes based on references that discuss teaching work through the collective and reflective bias in literacy action and we deal with the guidelines of the Training Notebooks of PNAIC 2012 and 2014. It is a qualitative research guided by the exploratory approach that had as a tool for data production a questionnaire that included a total of 22 literacy teachers working in the 3rd year. The data allow us to affirm that, in general, there is a planning practice that sometimes happens individually and sometimes collectively and that the working conditions of these professionals do not always favor meetings. We realized that the areas of knowledge most addressed by these literacy teachers are language and mathematics because they believe that in the 3rd year of the literacy cycle, the domain of reading and writing and mathematical concepts need to be consolidated. Finally, there is a strong trend towards integrated planning practices.
\end{abstract}

Keywords: Planning. Literacy. Pedagogical practices.

\section{Planificación de las clases en la vida diaria de alfabetización: prácticas, perspectivas y desafíos}

RESUMEN: En este texto presentamos los resultados de una encuesta realizada en 2018, con maestros de alfabetización de un municipio del interior de Rio Grande do Sul, que participaron en la capacitación dentro del alcance del Pacto Nacional para la Alfabetización a la edad adecuada - PNAIC 2017/2018. Problematizamos la práctica de planificar clases basadas en referencias que discuten el trabajo docente a través del sesgo colectivo y reflexivo en la acción de alfabetización y nos ocupamos de las pautas de los Cuadernos de capacitación de PNAIC 2012 y 2014. Es una investigación cualitativa guiada 
por el enfoque exploratorio que tuvo como herramienta para la producción de datos un cuestionario que incluyó a un total de 22 alfabetizadores trabajando en el 3er año. Los datos nos permiten afirmar que existe una práctica de planificación que a veces ocurre individualmente y otras colectivamente y que las condiciones de trabajo de estos profesionales no siempre favorecen las reuniones. Nos dimos cuenta de que las áreas de conocimiento más abordadas por estos maestros de alfabetización son el lenguaje y las matemáticas porque creen que en el tercer año del ciclo de alfabetización, el dominio de la lectura y la escritura y los conceptos matemáticos deben consolidarse. Finalmente, existe una fuerte tendencia hacia prácticas integradas de planificación.

Palabras-clave: Planificación. Alfabetización. Prácticas pedagógicas.

\section{Referência}

BATISTA, A. A. G. et al. Planejamento da alfabetização. Belo Horizonte: Ceale/FaE/UFMG, 2005.

BRASIL. Ministério da Educação; Secretaria de Educação Básica; Conselho Nacional de Educação; Câmara de Educação Básica. Base nacional comum curricular. Brasília, DF: MEC, 2018. Disponível em: http://basenacionalcomum.mec.gov.br/wpcontent/uploads/2018/04/ BNCC_19mar2018_versaofinal.pdf. Acesso em: 1 jul. 2019.

BRASIL. Ministério da Educação. Secretaria da Educação Básica. Base nacional comum curricular. Brasília, DF, 2017. Disponível em: http://basenacionalcomum.mec.gov.br/images/ bncc_ei_ef_110518_ versaofinal_site.pdf. Acesso em: 1 jul. 2019.

BRASIL. Ministério da Educação. Secretaria de Educação Básica. Diretrizes curriculares nacionais para o ensino fundamental. Brasília, DF: MEC: SEB, 2010.

BRASIL. Ministério da Educação. Secretaria de Educação Básica. Diretoria de Apoio à Gestão Educacional. Pacto nacional pela alfabetização na idade certa: planejamento escolar- alfabetização e ensino da língua portuguesa. Brasília, DF: MEC: SEB, 2012.

BRASIL. Ministério da Educação. Secretaria de Educação Básica. Diretoria de Apoio à Gestão Educacional. Pacto nacional pela alfabetização na idade certa: organização do trabalho pedagógico. Brasília, DF: MEC: SEB, 2014.

CORSINO, P. As crianças de seis anos e as áreas de conhecimento. In: BEAUCHAMP, J.; PAGEL, S. D.; NASCIMENTO, A. R do. (org.). Ensino fundamental de nove anos: orientações para a inclusão das crianças de seis anos de idade. Brasília, DF: MEC, SEB, 2007.

FERREIRA, A. T. B.; ALBUQUERQUE, E. B. C. de. As rotinas da escola e da sala de aula: referências para a organização do trabalho do professor alfabetizador. In: BRASIL. Pacto nacional pela alfabetização na idade certa. Planejamento escolar: alfabetização e ensino da língua portuguesa.

Brasília, DF: MEC, SEB, 2012. 
GIL, A. C. Métodos e técnicas de pesquisa social. 5. ed. São Paulo: Atlas, 1999.

IMBERNÓN, F. Formação permanente do professorado: novas tendências. Tradução Sandra Trabusco Valenzuela. São Paulo: Cortez, 2009.

IMBERNÓN, F. Formação continuada de professores. Porto Alegre: Artmed, 2010.

IMBERNÓN, F. Formação docente e profissional: formar-se para a mudança e a incerteza. 9. ed., São Paulo: Cortez, 2011.

LAVILLE, C.; DIONNE, J. A construção do saber: manual de metodologia da pesquisa em ciências. Tradução Heloisa Monteiro e Francisco Settineri. Porto Alegre: Artmed: Belo Horizonte: EdUFMG, 1999.

LEAL, T. F. Estabelecendo metas e organizando o trabalho: o planejamento no cotidiano docente. Olinda: Secretaria Municipal de Educação de Olinda, 2009. Mimeo.

MELO, E. P. C. B. N. PNAIC: uma análise crítica das concepções de alfabetização presentes nos cadernos de formação docente. 2015. Dissertação (Mestrado em Educação) - Centro de Ciências Humanas e Biológicas, Universidade Federal de São Carlos, Sorocaba, 2015.

MORAIS, A. G. de. Consciência fonológica na educação infantil e no ciclo da alfabetização. Belo Horizonte: Autêntica Editora, 2019.

NERY, A. Modalidades organizativas do trabalho pedagógico: uma possibilidade. Ensino fundamental de nove anos: orientações para a inclusão da criança de seis anos de idade. Brasília, DF: Ministério da Educação, Secretaria de Educação Básica, 2007.

NÓvOA, A. (org.). Profissão professor. Porto: Porto Editora,1991.

SÁ, C. F. de; LIMA, S. B. de Amorim. Ciclo de alfabetização e direitos de aprendizagem. In: BRASIL. Ministério da Educação. Secretaria de Educação Básica. Pacto nacional pela alfabetização na idade certa: currículo na perspectiva da inclusão e da diversidade: as diretrizes curriculares nacionais da educação básica e o ciclo de alfabetização. Brasília, DF: MEC, SEB, 2015. (Caderno 1).

SOARES, M. Alfabetização: em busca de um método? In: SOARES, M. Alfabetização e letramento. 2. ed. São Paulo: Contexto, 2004. p. 85-97.

PINHO, P. M. Currículo e alfabetização nos planos de estudos: construções interdiscursi- vas. 2006. Dissertação (Mestrado em Educação) Faculdade de Educação, Universidade Federal do Rio Grande do Sul, Porto Alegre, RS. 